\title{
Analysis of the decrease in the tropical mean outgoing shortwave radiation at the top of atmosphere for the period 1984-2000
}

\author{
A. Fotiadi ${ }^{2}$, N. Hatzianastassiou ${ }^{1,2}$, C. Matsoukas ${ }^{2,3}$, K. G. Pavlakis ${ }^{2}$, E. Drakakis ${ }^{2,4}$, D. Hatzidimitriou . $^{2,3}$, and \\ I. Vardavas ${ }^{2,3}$ \\ ${ }^{1}$ Laboratory of Meteorology, Department of Physics, University of Ioannina, Greece \\ ${ }^{2}$ Foundation for Research and Technology-Hellas, Heraklion, Crete, Greece \\ ${ }^{3}$ Department of Physics, University of Crete, Crete, Greece \\ ${ }^{4}$ Department of Electrical Engineering, Technological Educational Institute of Crete, Greece
}

Received: 19 October 2004 - Published in Atmos. Chem. Phys. Discuss.: 31 January 2005

Revised: 21 April 2005 - Accepted: 2 June 2005 - Published: 11 July 2005

\begin{abstract}
A decadal-scale trend in the tropical radiative energy budget has been observed recently by satellites, which however is not reproduced by climate models. In the present study, we have computed the outgoing shortwave radiation (OSR) at the top of atmosphere (TOA) at $2.5^{\circ}$ longitudelatitude resolution and on a mean monthly basis for the 17year period $1984-2000$, by using a deterministic solar radiative transfer model and cloud climatological data from the International Satellite Cloud Climatology Project (ISCCP) D2 database. Anomaly time series for the mean monthly pixel-level OSR fluxes, as well as for the key physical parameters, were constructed. A significant decreasing trend in OSR anomalies, starting mainly from the late 1980 s, was found in tropical and subtropical regions $\left(30^{\circ} \mathrm{S}-\right.$ $30^{\circ} \mathrm{N}$ ), indicating a decadal increase in solar planetary heating equal to $1.9 \pm 0.3 \mathrm{Wm}^{-2} /$ decade, reproducing well the features recorded by satellite observations, in contrast to climate model results. This increase in solar planetary heating, however, is accompanied by a similar increase in planetary cooling, due to increased outgoing longwave radiation, so that there is no change in net radiation. The model computed OSR trend is in good agreement with the corresponding linear decadal decrease of $2.5 \pm 0.4 \mathrm{Wm}^{-2} /$ decade in tropical mean OSR anomalies derived from ERBE S-10N nonscanner data (edition 2). An attempt was made to identify the physical processes responsible for the decreasing trend in tropical mean OSR. A detailed correlation analysis using pixel-level anomalies of model computed OSR flux and ISCCP cloud cover over the entire tropical and subtropical region $\left(30^{\circ} \mathrm{S}-30^{\circ} \mathrm{N}\right)$, gave a correlation coefficient of 0.79 , indicating that decreasing cloud cover is the main reason for the tropical OSR trend. According to the ISCCP-D2 data
\end{abstract}

Correspondence to: N. Hatzianastassiou

(nhatzian@cc.uoi.gr) derived from the combined visible/infrared (VIS/IR) analysis, the tropical cloud cover has decreased by $6.6 \pm 0.2 \%$ per decade, in relative terms. A detailed analysis of the interannual and long-term variability of the various parameters determining the OSR at TOA, has shown that the most important contribution to the observed OSR trend comes from a decrease in low-level cloud cover over the period 19842000 , followed by decreases in middle and high-level cloud cover. Note, however, that there still remain some uncertainties associated with the existence and magnitude of trends in ISCCP-D2 cloud amounts. Opposite but small trends are introduced by increases in cloud scattering optical depth of low and middle clouds.

\section{Introduction}

The climate of the Earth-atmosphere system is driven by the Earth's radiation budget. Clouds interact with radiation playing thus a key role for the Earth's radiation balance, and hence they strongly affect the Earth's climate. However, cloud-radiation interactions currently introduce the largest uncertainty in climate variability and climatic change prediction through various feedback processes (IPCC, 2001).

In the last few years, there is increasing evidence of a large decadal trend in the top of atmosphere (TOA) tropical radiation budget, attributed to changes in cloud amount (Wielicki et al., 2002a,b; Allan and Slingo, 2002; Chen et al., 2002; Lin et al., 2004; Zhang et al., 2004). Wielicki et al. (2002a,b) analysed satellite broadband observations from the Earth Radiation Budget Satellite (ERBS), Wide Field of View (WFOV), Earth Radiation Budget Experiment (ERBE/ERBS scanner), Scanner for Radiation Budget (ScaRaB), Clouds and the Earth's Radiation Energy System (CERES) of the 
outgoing longwave (OLR) and shortwave radiation (OSR) at TOA over the 22-year period 1979-2001, and reported a significant decadal-scale variation of $\sim 3 \mathrm{Wm}^{-2}$ in the tropical OLR and OSR at TOA. They suggested that this variation is caused by changes in tropical cloudiness. Chen et al. (2002) using ISCCP data, also reported that there has been a corresponding variation in total cloud amount in tropical and sub-tropical regions, over the same period, that might explain the SW radiative flux anomalies. They provide evidence that these cloudiness changes are related to changes in vertical air-motion possibly associated with a strengthening of the tropical Hadley and Walker circulations. Jacobowitz et al. (2003) using the Advanced Very High Resolution Radiometer (AVHRR) Pathfinder Atmosphere (PATMOS) climate data set, examined the time series of the OSR at TOA in the tropics $\left(20^{\circ} \mathrm{S}-20^{\circ} \mathrm{N}\right)$, and found that tropical PATMOS and ERBS OSR fluxes are in quite good agreement. However, for the OLR at TOA they found no significant long-term trend in the corrected PATMOS data against the significant increasing trend found in ERBE OLR fluxes. Hatzidimitriou et al. (2004) performed an analysis on the tropical OLR at TOA and its causes. They have reported a decadal increase in OLR at TOA of $1.9 \pm 0.2 \mathrm{Wm}^{-2}$, mainly attributed to a decrease in high-level cloud cover over the period 1984-2000, followed by a drying of the upper troposphere and a decrease in low-level cloudiness. Zhang et al. (2004) calculated time-series of monthly mean TOA SW and LW fluxes from ISCCP-FD data, confirming that there is a decadal variation in the tropical mean radiative energy budget. It is noteworthy that climate models studied by Wielicki et al. (2002) and Allan and Slingo (2002), failed to reproduce this variation in the tropical energy budget, as measured by satellites, with the currently used climate forcings, due to either some additional external forcing or some internal physical processes which are not included in the climate models (Allan and Slingo, 2002). Most of the existing studies, however, give more emphasis to the decadal trend in OLR rather than OSR flux at TOA, probably because it is generally more difficult to obtain correct SW than LW fluxes in climate models (Wielicki et al., 2002a, data supplement http://www.sciencemag.org/ cgi/content/full/295/5556/841/DC1). Besides, in most cases, the existing studies do not examine the causes of the decadal scale trends.

Recently Hatzianastassiou et al. (2004a), using a deterministic radiative transfer model along with ISCCP-D2 data, reported a decreasing trend in the OSR flux at TOA, of $2.3 \mathrm{Wm}^{-2}$ on a global scale, over the 14 -year period 1984 1997. This global OSR trend was ascribed to low latitudes, while clouds, as given by ISCCP, were identified as the most likely source. However, there is still some debate on whether the decreasing trend in cloud amount is physical or not. More detailed investigations are necessary. For example, the relationship between the OSR anomaly and the anomalies in cloud amount of different cloud types (e.g. low, mid and high-level) should be determined. Ellis et al. (2004) em- ploying cloud amount data from the ISCCP-D2 and CLAUS (Hodges et al., 2000) dataset (which is, however, based upon ISCCP-B3) provided strong evidence that the cloud amount trend, especially in the tropics, is physical and robust, and that it is significantly correlated with various dynamical parameters.

In this study, we extend the work by Hatzianastassiou et al. (2004a), by focusing on the tropical and subtropical regions $\left(30^{\circ} \mathrm{S}-30^{\circ} \mathrm{N}\right)$. We attempt to analyse in detail trends in OSR flux by using model computations and satellite observations, and to identify and quantify their probable causes, Thus we compute the tropical OSR flux at TOA over the extended 17-year time period from 1984 to 2000 by using a deterministic radiative transfer model, cloud data from ISCCP$\mathrm{D}$, and atmospheric and humidity data from NCEP/NCAR and ECMWF reanalysis projects. Anomaly time series of the OSR at TOA, as well as of the key input climatological data, averaged over tropical and subtropical regions $\left(30^{\circ} \mathrm{S}-30^{\circ} \mathrm{N}\right)$, were constructed to investigate any existing trend. The model OSR anomalies have been compared with those obtained from the Earth Radiation Budget Experiment (ERBE, Barkstrom et al., 1989) ERBS S-10N (WFOV NF edition 2) non-scanner data. Our model results show that, contrary to climate models, the deterministic radiative transfer model can reproduce well the long-term variability in the tropical SW radiation budget at TOA. The sources of this long-term OSR trend were further investigated, and the effect of any long-term changes detected in the time series of the model input data, to changes in the OSR at TOA, was examined.

\section{Model and input data}

The radiative transfer model used to compute the TOA OSR fluxes, is described in detail by Hatzianastassiou et al. (2004a), Hatzianastassiou and Vardavas $(1999,2001)$ and Vardavas and Koutoulaki (1995). The model takes into account the presence of ozone $\left(\mathrm{O}_{3}\right)$, water vapour $\left(\mathrm{H}_{2} \mathrm{O}\right)$, carbon dioxide $\left(\mathrm{CO}_{2}\right)$, aerosol particles, Rayleigh scattering, surface reflection, and clouds (low, middle, high). Cloud climatological data such as cloud cover and cloud optical thickness are taken from the ISCCP-D2 dataset (Rossow et al., 1996; Rossow and Schiffer, 1999) and they are treated as in Hatzianastassiou et al. (2004a). It should be noted that we have used in this study the ISCCP-D2 individual cloud data derived from the visible/infrared (VIS/IR) analysis rather than the low-, mid- and high-level cloud data (as classified according to the ISCCP scheme), also provided by ISCCP-D2 and derived using the IR-only analysis. This is done because the combined VIS/IR analysis is of better quality than the IR-only one during daytime (Rossow et al., 1996), and thus the VIS/IR cloud products are more appropriate for SW radiation budget studies. Moreover, the VIS/IR (individual) cloud data were found to dramatically improve 

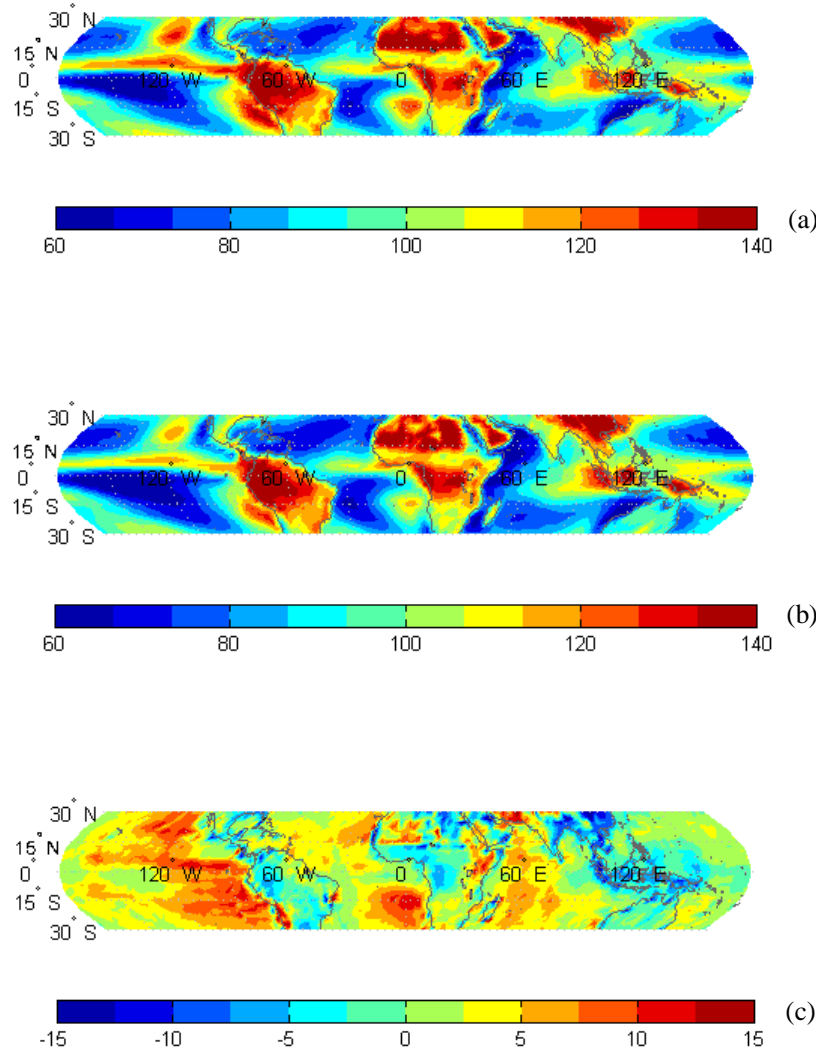

Fig. 1. Geographical distribution of the outgoing shortwave radiation (OSR in $\mathrm{Wm}^{-2}$ ) at the top of atmosphere (TOA), (a) as calculated by the model and (b) as derived by ERBE-S4 scanner data. Both give the annual long-term average calculated over the 60month period covered by the ERBE-S4 dataset (1985-1989). Figure (c) gives the difference in OSR at TOA between the model computations and ERBE-S4 data.

the SW model results at both TOA and surface, in terms of comparison with ERBE-S4 scanner satellite data and Baseline Surface Radiation Network (BSRN) and Global Energy Balance Archive (GEBA) site measurements, respectively.

Climatological vertical distributions of temperature and water vapour as well as data of surface pressure, which are used for the model's topography scheme, are taken either from the NCEP/NCAR or the ECMWF Global Reanalysis Projects. Total $\mathrm{O}_{3}$ column abundance data are taken from the Television Infrared Observational Satellite (TIROS) Operational Vertical Sounder (TOVS) database, whereas aerosol optical properties, i.e. aerosol optical thickness (AOT), single scattering albedo $\left(\omega_{a e r}\right)$ and asymmetry parameter $\left(g_{a e r}\right)$, are taken from the Global Aerosol Data Set (GADS) (Koepke et al., 1997), and they are treated as in Hatzianastassiou et al. (2004b).

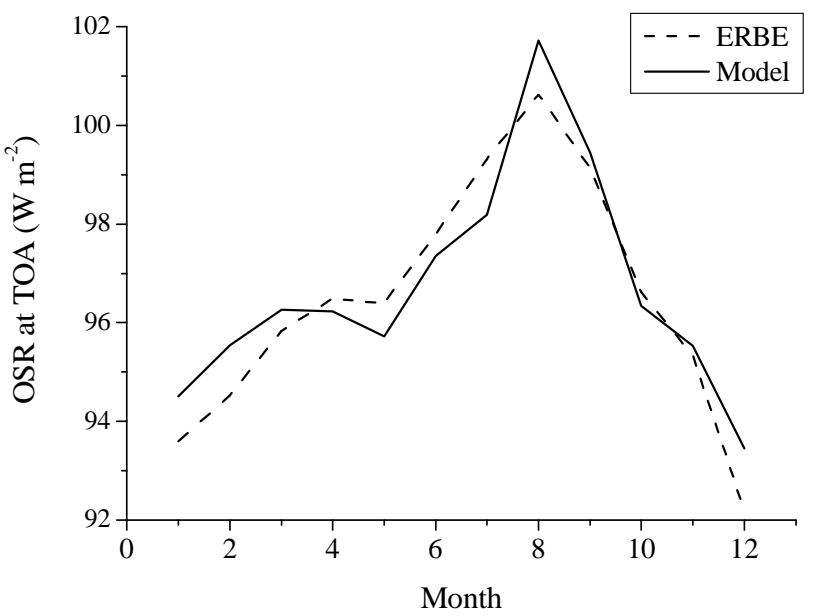

Fig. 2. Average seasonal cycle displayed by the model OSR (solid line) and the ERBE OSR (dashed line), after having subtracted from the model data the value of $1.5 \mathrm{Wm}^{-2}$ (model bias).

\section{Model validation}

The model mean monthly OSR fluxes at TOA were validated against high-quality ERBE-S4 scanner data for each $2.5^{\circ} \times 2.5^{\circ}$ latitude-longitude region for the years 1985-1989 (for which ERBE-S4 data are available). The validation was performed at pixel level for all pixels within the $30^{\circ} \mathrm{S}-30^{\circ} \mathrm{N}$ zone, providing good agreement, with a correlation coefficient $\mathrm{R}$ equal to 0.96 . The mean difference between model and ERBE fluxes is $1.5 \mathrm{Wm}^{-2}$ with a standard deviation of $8.6 \mathrm{Wm}^{-2}$. Figure 1 shows the geographical distribution of the 5-year annual average of OSR at TOA as computed with our model and as derived by ERBE-S4 data, as well as the differences between the model results and the ERBE-S4 data. There is very good agreement with differences less than $5 \%$ over most pixels in the study region. Also, our model reproduces very well the 5-year average annual cycle of OSR over the tropical and subtropical region, as given by ERBE (Fig. 2). Given that the ERBE-S4 scanner data (1985-1989) do not provide long-term time series, the long-term (19851999) ERBE S-10N (WFOV NF edition 2) non-scanner data were also used to serve for intercomparison with our model results (see next section). Note that in this case, our model results were downscaled to $5^{\circ}$ longitude-latitude resolution, to meet the spatial resolution of the ERBE S-10N data.

\section{Results and discussion}

4.1 Tropical interannual OSR flux anomalies: model versus ERBE S-10N

Hatzianastassiou et al. (2004a) have reported a decreasing trend in the global mean OSR over the 14-year period 19841997 claiming that this trend is attributed to low latitudes. In 


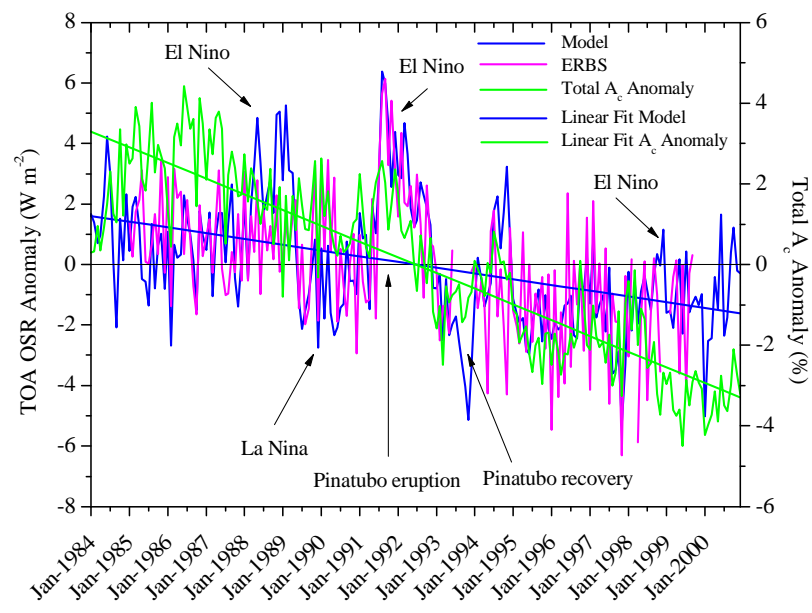

Fig. 3. Time series of tropical $\left(30^{\circ} \mathrm{S}-30^{\circ} \mathrm{N}\right)$ mean model (blue line) and ERBE S-10N (magenta line) top of atmosphere (TOA) outgoing shortwave radiation (OSR) anomalies (in $\mathrm{Wm}^{-2}$ ), and ISCCP-D2 total cloud cover $\left(A_{c}\right)$ anomalies (in \%) (green line), over the time period 1984-2000. Linear regression fits to the model OSR flux anomaly (blue line) and $\mathrm{A}_{c}$ anomaly (green line) are also shown.

this study, we have extended the study period up to 17 years, i.e. from January 1984 through December 2000, and focus on the zone $30^{\circ} \mathrm{S}-30^{\circ} \mathrm{N}$ where, according to satellite observations, there is a significant trend in OSR. Inter-annual deseasonalised (i.e. from which the average seasonal cycle has been removed) anomalies of the mean monthly OSR fluxes averaged over the zone $30^{\circ} \mathrm{S}-30^{\circ} \mathrm{N}$, for the period 1984 to 2000, were calculated with the model and are shown in Fig. 3 (blue line).

The OSR anomaly shows great variation, up to $\pm 6 \mathrm{Wm}^{-2}$ above or below the 17-year mean. Interesting features can be seen in Fig. 3, which are due to El Niño and La Niña events and to Mount Pinatubo eruption (cf. Wielicki et al., 2002a). The increase in the reflected OSR at TOA within the year following the Pinatubo eruption is in good agreement with ERBE S-10N data as shown here (magenta line), as well as with PATMOS data (Jacobowitz et al., 2003). This rapid increase in OSR is followed by a recovery period. The effects of the strong 1997/1998 El Niño event that were evident in the observed and simulated OLR flux anomalies (Wielicki et al., 2002; Allan and Slingo, 2002; Hatzidimitriou, et al., 2004) are not so evident here, although an associated peak exists, consisting in an OSR anomaly that passes from large negative values (about $-6 \mathrm{Wm}^{-2}$ ) to positives ones $\left(\sim 1.5 \mathrm{Wm}^{-2}\right)$. However, as will be discussed below, a strong peak related to the 1997/1998 El Niño event appears in the zone $0^{\circ}-10^{\circ} \mathrm{S}$ (cf. Fig. 6). Overall, the mean tropical OSR flux is found to have decreased over the period 1984-2000. The cloud cover $\left(A_{c}\right)$ variability, in terms of anomaly time series, over the same period (1984-2000) and the same region $\left(30^{\circ} \mathrm{S}-30^{\circ} \mathrm{N}\right)$ as for OSR, is also given in
Fig. 3. The $A_{c}$ anomalies were derived from the ISCCP-D2 monthly mean data as differences from the 17-year averages. Note that the strong positive anomalies during the summer of 1991 are mostly attributed to low-level clouds and secondarily to mid-level ones. This is due to the fact that after the Mt. Pinatubo eruption, the VIS/IR ISCCP $A_{c}$ data indicate a notable decrease of thin cirrus over oceans, accompanied by a comparable increase of altocumulus and cumulus clouds; over land, there are no significant changes (Luo et al., 2002). However, this is a temporary local effect, since the Mt. Pinatubo volcanic aerosol did not have a significant systematic effect on tropical cirrus properties such as cloud amount or optical thickness, as reported by Luo et al. (2002). This is an example of how changes in ISCCP radiances that are not related to clouds may be interpreted incorrectly as cloud effects by ISCCP. Nevertheless, even in such a case of spurious change in ISCCP cloud data, realistic changes in radiative fluxes can result by using these data.

Linear regressions to the OSR and $A_{c}$ anomalies are also given in Fig. 3. The time series of OSR anomaly, exhibit a significant long-term decreasing trend in the tropical and sub-tropical latitudes, well illustrated by the fitted linear regression. More specifically, the model computed OSR anomaly yields a linear decadal decrease equal to $1.9 \pm 0.3 \mathrm{Wm}^{-2} / \mathrm{dec}$ ade. At the beginning of the study period, i.e. around the mid 1980s, the OSR anomaly is slightly positive, varying around $2 \mathrm{Wm}^{-2}$, while there is a drop from the late $1980 \mathrm{~s}$, down to values of $-2 \mathrm{Wm}^{-2}$. The positive OSR anomalies at the beginning of the study period are probably due to the influence of the El-Chichon eruption that took place in the spring of 1982.

Our model's decadal decreasing trend of $1.9 \pm 0.3 \mathrm{Wm}^{-2}$ in tropical and subtropical OSR anomaly is in quite good agreement with the revised value of $2.5 \mathrm{Wm}^{-2}$ for the OSR flux decrease given by Wielicki et al. (2002b), whereas recent corrections to the ERBE S-10N non-scanner data has resulted in a trend equal to $2.1 \mathrm{Wm}^{-2}$ (Wielicki, personal communication). In terms of comparison with our model results, the corresponding tropical $\left(30^{\circ} \mathrm{S}-30^{\circ} \mathrm{N}\right)$ mean OSR anomaly as derived from the ERBE S-10N (WFOV NF edition 2) nonscanner data is overlaid on Fig. 3. There is good agreement between the two time series. The linear decrease in tropical OSR anomalies derived by ERBE S-10N data is equal to $2.5 \pm 0.4 \mathrm{Wm}^{-2} /$ decade, very close to our model computed value of $1.9 \pm 0.3 \mathrm{Wm}^{-2} /$ decade. The slightly larger variability of ERBE anomalies is probably due to the fact that there are missing $2.5^{\circ} \times 2.5^{\circ}$ latitude-longitude region data in the ERBE S-10N in latitudes between $20^{\circ}$ and $30^{\circ}$ in both hemispheres. Consequently, our deterministic radiative transfer model is able to reproduce the decadal-scale trend and the observed patterns of the long-term variability in the OSR at TOA radiative flux anomalies over the tropical regions. 
4.2 Correlation analysis of OSR flux and ISCCP cloud anomalies

It has been suggested (Wielicki et al., 2002a; Chen et al., 2002) that the large decadal variability in tropical OSR is caused by changes in tropical cloudiness. Recently, Hatzianastassiou et al. (2004), based on a sensitivity study, have also reported that the long-term decreasing trend in global mean OSR flux is mostly attributed to cloud cover. In this study, we have performed a thorough analysis identifying clouds as the main source of the model computed decreasing trend in OSR anomalies. At first, this is indicated by the patterns in the tropical mean cloud cover anomalies shown in Fig. 3; these patterns match very well those of OSR flux anomalies. Thus, the tropical cloud cover anomalies depict a decreasing trend, starting from the early 1990s. From 1984 through the late 1980s, the cloud cover has positive anomalies of about 2-4\% above the 17-year mean, while after the early 1990 s the total $A_{c}$ anomaly steadily decreases through the late 1990s, reaching values around $4 \%$ below the longterm mean value. The overall computed linear decreasing trend in total cloud cover is equal to $6.6 \pm 0.2 \%$ per decade ${ }^{11}$.

To further investigate and quantify the apparent correlation between the anomalies of OSR flux and total cloudiness over the tropical region $30^{\circ} \mathrm{S}-30^{\circ} \mathrm{N}$, we performed a correlation analysis between the anomalies of model OSR flux and total $A_{c}$ at $2.5^{\circ} \times 2.5^{\circ}$ pixel level and on monthly mean basis, for the 17-year period from January 1984 to December 2000; the relevant scatterplot is shown in Fig. 4. The total 704658 pixel matched data pairs give a correlation coefficient equal to 0.79 , indicating that the decrease in tropical cloud cover is mostly responsible for the satelliteobserved and model computed decadal trend (decrease) in tropical OSR at TOA. Of course, cloud amount is a major determinant of OSR flux in our model (see Hatzianastassiou et al., 2004a), though it is not the only one; for example the cloud optical depth and cloud asymmetry parameter also influence significantly the OSR. In this sense, the correlation between the OSR flux anomalies and those of cloud amount may be considered as some type of model sensitivity. To check the representativeness of the correlation results of Fig. 4a, we have also performed another correlation between the ERBE-S4 OSR flux anomalies and those of ISCCP-D2 cloud amount (Fig. 4b). This was done for the period 19851989 based on the availability of ERBE-S4 data. The total number of 207360 pixel matched data pairs give a correlation coefficient equal to 0.69 , close to the coefficient of 0.79 from the correlation between model OSR flux and ISCCPD2 $A_{c}$ anomalies for the 17-year period 1984-2000. In particular, to get the comparison between the two correlations more consistent, we have repeated the correlation between the model OSR flux and ISCCP-D2 $A_{c}$ anomalies, but for

\footnotetext{
${ }^{1}$ Estimated percent decadal trend $=100 *$ (parameter decadal change)/(17-year average)
}
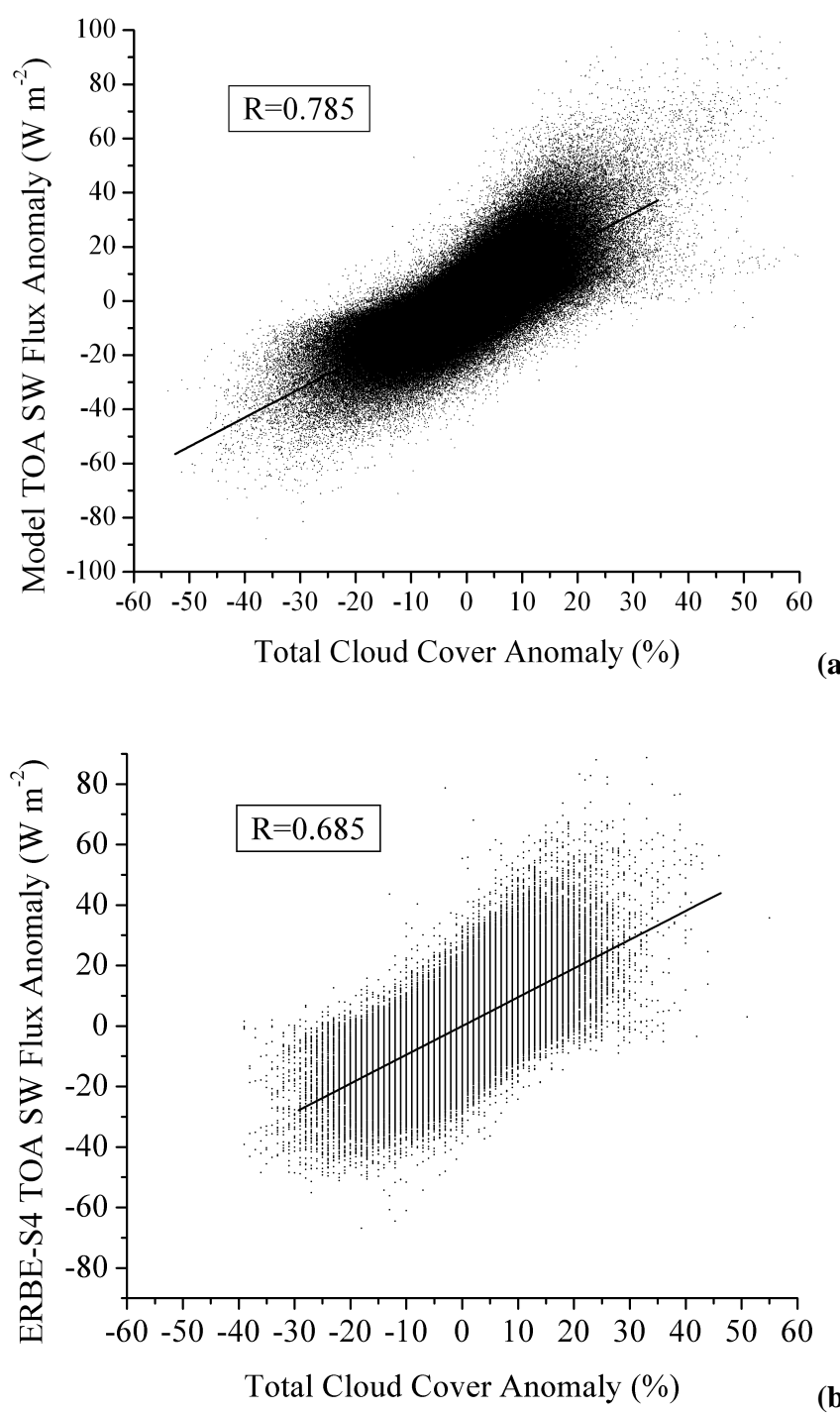

(b)

Fig. 4. Scatterplot comparison between (a) the pixel-level monthly mean model computed top of atmosphere (TOA) outgoing shortwave flux anomalies (in $\mathrm{Wm}^{-2}$ ) and the ISCCP-D2 total cloud cover anomalies $(\%)$ for the region $30^{\circ} \mathrm{S}-30^{\circ} \mathrm{N}$, over the period 1984-2000, and (b) the monthly mean ERBE-S4 TOA outgoing shortwave flux anomalies (in $\mathrm{Wm}^{-2}$ ) and the ISCCP-D2 total cloud cover anomalies $(\%)$ for the region $30^{\circ} \mathrm{S}-30^{\circ} \mathrm{N}$, over the period 1985-1989. A total number of 704658 and 207360 box matched data pairs are plotted, respectively, and the fitted linear regressions and correlation coefficients $(\mathrm{R})$ are also given.

the 5-year (1985-1989) period. The correlation coefficient was found to be equal to 0.76 , i.e. very close to 0.69 . Consequently, the correlation results between model OSR flux and ISCCP-D2 $A_{c}$ anomalies for the 17-year period (1984-2000) are consistent and realistic and support our conclusion that the computed decadal decreasing trend in tropical OSR flux is due to decreasing tropical cloud cover. However, it should be pointed out that, in contrast to the ISCCP-D2 $A_{c}$ data, no 
Table 1. Correlation coefficient (R) values of the scatter plot comparison between the pixel-level monthly mean top of atmosphere (TOA) outgoing shortwave radiation (OSR) anomalies and total cloud cover $\left(A_{C}\right)$ anomalies for each $10^{\circ}$ latitude zone between $30^{\circ} \mathrm{S}-30^{\circ} \mathrm{N}$, over the time period $1984-2000$.

\begin{tabular}{cc}
\hline Zones $\left({ }^{\circ}\right)$ & $\mathrm{R}\left(\mathrm{OSR}-\right.$ total $\left.A_{c}\right)$ \\
\hline $20^{\circ}-30^{\circ} \mathrm{N}$ & 0.76 \\
$10^{\circ}-20^{\circ} \mathrm{N}$ & 0.77 \\
$0^{\circ}-10^{\circ} \mathrm{N}$ & 0.81 \\
$10^{\circ}-0^{\circ} \mathrm{S}$ & 0.81 \\
$20^{\circ}-10^{\circ} \mathrm{S}$ & 0.78 \\
$30^{\circ}-20^{\circ} \mathrm{S}$ & 0.79 \\
\hline
\end{tabular}

trend is found in the adjusted AVHRR PATMOS time series of cloud amount. Besides, no systematic trends are noticed in the PATMOS tropical OSR and OLR fluxes (Jacobowitz et al., 2003), compared to ERBE S-10N. Note also that there is a decreasing trend in the cloud amount time series from the CLAUS dataset (Hodges et al., 2000), which is consistent with that of ISCCP-D2 $A_{c}$ data (Ellis et al., 2004). Moreover, the trend in ISCCP cloud data may still be uncertain to some extent, for example due to the view angle dependence (Campbell, 2004). Thus, overall, it is very interesting that in this study using cloud data derived from the ISCCP-D2 along with surface and atmospheric data from reanalysis projects, we compute a decreasing trend in OSR at TOA, which is in good agreement with the trend found in ERBE S-10N corrected records.

In order to investigate the covariability of the anomalies of OSR at TOA and cloudiness at global scale, the 17-year (1984-2000) time series of monthly mean $10^{\circ}$ zonally averaged model-based OSR flux and ISCCP-D $2 A_{c}$ anomalies were constructed and are plotted in Figs. 5 and 6. For each $10^{\circ}$ latitude zone, linear regression fits are also plotted for both OSR and $A_{c}$ anomalies. There is an apparent correlation between the long-term model-based OSR and $A_{c}$ anomalies, especially in low and middle latitudes. Besides, there are significant decreasing trends in both OSR and $A_{c}$ anomalies in the latitudes between $50^{\circ} \mathrm{S}$ and $60^{\circ} \mathrm{N}$, especially between $30^{\circ} \mathrm{S}-30^{\circ} \mathrm{N}$. We have computed the correlation coefficients of the scatterplot comparison between the pixel-level monthly mean model-based TOA OSR flux anomalies and total $A_{c}$ anomalies for each $10^{\circ}$ latitude zone, over the period 1984-2000. Table 1 summarises the correlation coefficients for each $10^{\circ}$ zone between $30^{\circ} \mathrm{S}-30^{\circ} \mathrm{N}$, although computations have been also performed for the rest of the globe. Nevertheless, values are not given for latitudes poleward of $30^{\circ} \mathrm{N}$ and $\mathrm{S}$ since, according to our analysis, the OSR and total $A_{c}$ anomalies are mostly correlated in the zones between $30^{\circ} \mathrm{S}$ and $30^{\circ} \mathrm{N}$, with correlation coefficients ranging from 0.76 to 0.81 . The strongest correlation is found in the trop-
Table 2. Decadal linear trend in low-, mid- and high-level cloud cover $\left(A_{c}\right)$, cloud absorption optical depth $\left(\tau_{c}^{a}\right)$, cloud scattering optical depth $\left(\tau_{c}^{s}\right)$, total precipitable water $\left(\mathrm{W}_{\mathrm{H}_{2} \mathrm{O}}\right)$, and total ozone column abundance $\left(\mathrm{W}_{\mathrm{O}_{3}}\right)$ for the $30^{\circ} \mathrm{S}-30^{\circ} \mathrm{N}$ region, and the corresponding induced changes (radiative forcing in $\mathrm{Wm}^{-2}$ ) in the outgoing shortwave radiation (OSR) at the top of atmosphere (TOA).

\begin{tabular}{lcc}
\hline Parameter & Decadal Trend $(\%)$ & $\begin{array}{c}\text { OSR radiative forcing } \\
\text { at TOA }\left(\mathrm{Wm}^{-2}\right)\end{array}$ \\
\hline$A_{c}-$ Low & $-9.9 \pm 0.8$ & $3.1 \downarrow$ \\
$A_{c}-$ Middle & $-6.6 \pm 0.8$ & $1.2 \downarrow$ \\
$A_{c}-$ High & $-3.0 \pm 0.9$ & $1.0 \downarrow$ \\
Low- $\tau_{c}^{a}$ & $2.8 \pm 1.0$ & $0.16 \downarrow$ \\
Middle- $\tau_{c}^{a}$ & $3.1 \pm 1.1$ & $0.11 \downarrow$ \\
High- $\tau_{c}^{a}$ & $-5.0 \pm 1.4$ & $0.02 \uparrow$ \\
Low- $\tau_{c}^{s}$ & $4.0 \pm 0.9$ & $0.9 \uparrow$ \\
Middle- $\tau_{c}^{s}$ & $4.9 \pm 0.8$ & $0.62 \uparrow$ \\
High- $\tau_{c}^{s}$ & $-0.3 \pm 1.9$ & $0.08 \downarrow$ \\
$\mathrm{W}_{\mathrm{H}_{2} \mathrm{O}}$ & $-1.2 \pm 0.3$ & $0.04 \uparrow$ \\
$\mathrm{W}_{\mathrm{O}_{3}}$ & $-1.3 \pm 0.2$ & $0.11 \uparrow$ \\
\hline
\end{tabular}

ical latitudes $0^{\circ}-10^{\circ} \mathrm{N}$ and S. Indeed, Figs. 5 and 6 confirm that anomalies of model-based OSR flux and total $A_{c}$ have very similar inter-annual variability patterns between $10^{\circ} \mathrm{S}-$ $10^{\circ} \mathrm{N}$, but also between $30^{\circ} \mathrm{S}$ and $30^{\circ} \mathrm{N}$. The correlation coefficient values gradually drop down to 0.41 towards the middle latitudes, and to no significant values in polar areas. Note that, as it has been already mentioned, the El Niño event of $1997 / 1998$ is clearly indicated in the zone $0^{\circ}-10^{\circ} \mathrm{S}$, in both OSR and $A_{c}$ anomalies. Actually, the zonal mean OSR anomalies reach values up to about $10 \mathrm{Wm}^{-2}$ from January through March of 1998 in zone $0^{\circ}-10^{\circ} \mathrm{S}$. These large anomalies, are related to the westward extension of the convection across the tropical Pacific and over the South Pacific convergence zone, i.e. over areas characterised by positive OSR anomalies as large as $100 \mathrm{Wm}^{-2}$. According to our analysis using ISCCP data, the decreasing trend in total cloudiness in areas between $30^{\circ} \mathrm{S}-30^{\circ} \mathrm{N}$ is primarily attributed to lowlevel clouds and much less to mid- and high-level clouds, except for a few cases, such as $20^{\circ} \mathrm{S}-30^{\circ} \mathrm{S}$ and $30^{\circ} \mathrm{S}-40^{\circ} \mathrm{S}$, where the high-level clouds show a stronger decreasing trend than low- or mid-level ones.

We have attempted to determine which of the main climatological parameters (described in Sect. 2) that determine the OSR at TOA, contribute significantly to the observed mean tropical OSR trend (as computed by our model) for the period 1984-2000. The methodology is the following: the anomaly time series of each input parameter were constructed for the period $1984-2000$ and for the region $30^{\circ} \mathrm{S}-30^{\circ} \mathrm{N}$, in exactly the same way as for the OSR and total cloud cover anomaly time series. Then, the existence of any long-term trend was quantified by applying a simple linear regression analysis, and whenever a statistically significant long-term trend was 

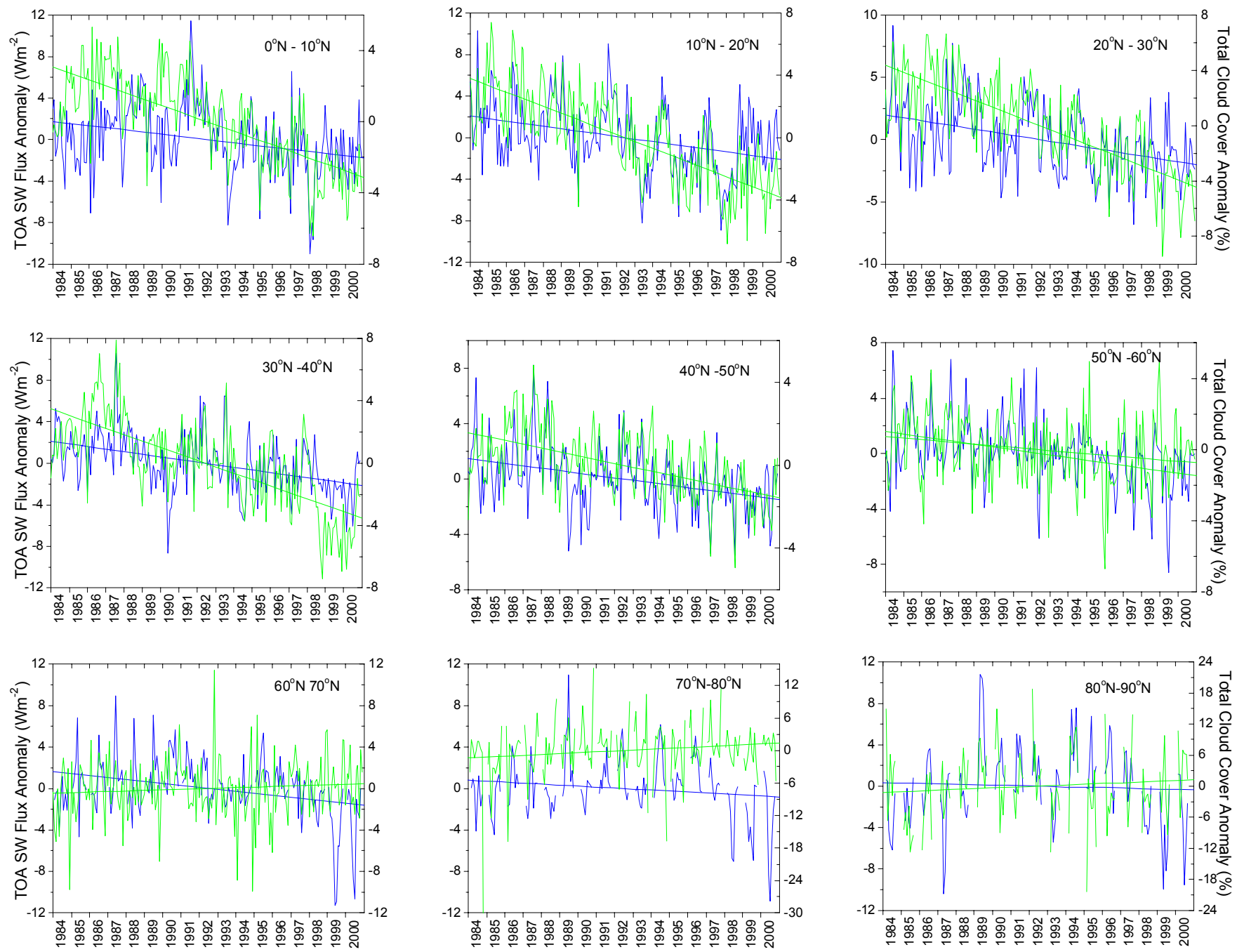

Fig. 5. Time series of $10^{\circ}$ latitude zonal averages of the anomalies of top of atmosphere (TOA) outgoing shortwave radiation (OSR) flux (in $\mathrm{Wm}^{-2}$, blue lines) and total cloud cover (\%, green lines) for the North Hemisphere, over the period 1984-2000. Linear regression fits to the OSR and $A_{c}$ anomalies are also displayed.

found for a parameter, this was introduced for the particular parameter in the model. To assess the statistical significance of long-term terms, the Mann-Kendall test was applied to the anomaly time-series. The OSR at TOA for each year of the study period (1984-2000), and the induced overall change in OSR (in $\mathrm{Wm}^{-2}$ ) was computed. Table 2 summarises the results of this analysis. All cloud types show a linearly decreasing trend over the study period, with the low-level clouds having the largest trend, equal to $-3.9 \pm 0.3 \%$ in absolute values or $-9.9 \pm 0.8 \%$ per decade in relative terms. Of course, there are still some uncertainties, since the changes in low-level clouds derived from the ISCCP-D2 data, are not necessarily consistent with changes derived from the second Stratospheric Aerosols and Gas Experiment (SAGE II, Wang et al., 2002) and synoptic observations (Norris, 1999). Nevertheless, note that SAGE II tropical clouds refer to up- permost opaque clouds (with vertical optical depth greater than 0.025 at $1.02 \mu \mathrm{m}$ ), while the aforementioned synoptic cloud observations are taken over oceans only. The midlevel clouds decreased by $1.4 \pm 0.2 \%$ in absolute values or by $6.6 \pm 0.8 \%$ per decade in relative terms, while the high-level ones also decreased by $1.2 \pm 0.4 \%$ or $3 \pm 0.9 \%$ per decade in relative terms, i.e. less than low and middle clouds. Thus, the VIS/IR mean tropical $\left(30^{\circ} \mathrm{S}-30^{\circ} \mathrm{N}\right)$ low-level clouds are found to have undergone the greatest decrease during the period 1984-2000, in agreement with the findings of Chen et al. (2002) and Lin et al. (2004). As for the other parameters, the cloud absorption optical depth for low and middle clouds has increased by $2.8 \pm 1 \%$ and $3.1 \pm 1.1 \%$ per decade, respectively, whereas that of high-level clouds decreased by $5 \pm 1.4 \%$ per decade. The corresponding values for the cloud scattering optical depth are equal to $4 \pm 0.9 \%, 4.9 \pm 0.8 \%$ and 

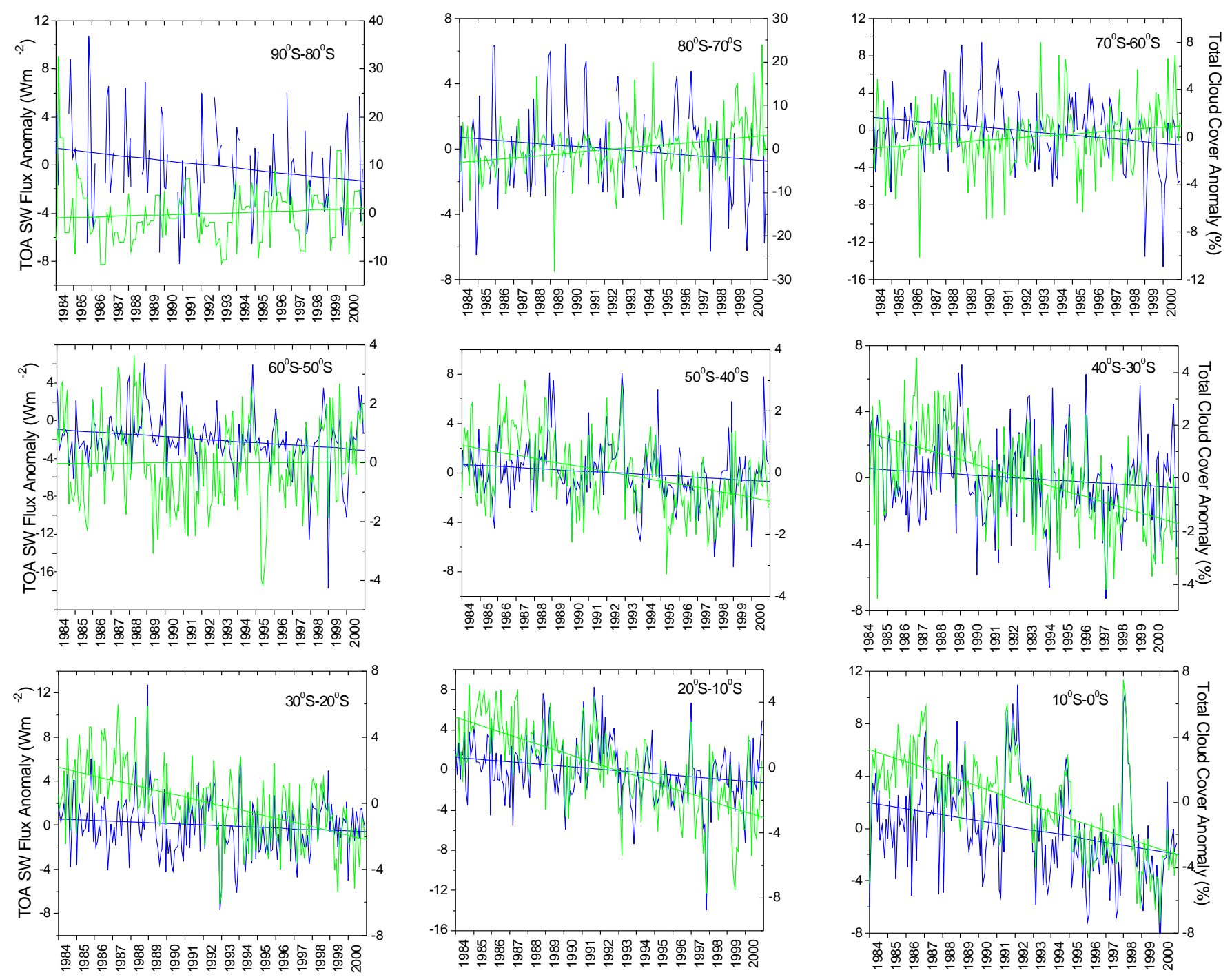

Fig. 6. As in Fig. 5, but for the South Hemisphere.

$-0.3 \pm 1.9 \%$ per decade for the low-, mid- and high-level clouds, respectively (the high-level clouds have no significant trend because of large error). Finally, total precipitable water and total ozone column abundance show small decreasing decadal trends although reduced precipitable water in NCEP was shown to be spurious compared with Special Sensor Microwave/Imager (SSM/I) data (e.g. Allan et al., 2004).

According to Table 2, the decrease in low-level cloud amount results in a significant decrease in OSR at TOA of $3.1 \mathrm{Wm}^{-2}$, whereas the decreases in mid- and high-level cloud cover have induced smaller decreases in OSR, equal to 1.2 and $1.0 \mathrm{Wm}^{-2}$, respectively. This is normal since (i) the decrease in low-level $A_{c}$ is larger than that for midand high-level $A_{c}$ (as shown in Table 2), and (ii) the OSR is more sensitive to low clouds rather than to mid- or highlevel clouds, as shown by a sensitivity study performed by
Hatzianastassiou et al. (2004a); the latter is due to the optically thicker low-level than higher clouds, especially over southern subtropical oceans. Although the computed decrease in mid-level clouds is greater than that of high-level clouds, the corresponding decrease in OSR induced by the middle clouds is almost equal to the OSR decrease introduced by high-level clouds. This can be explained by the fact that OSR is more sensitive to high-level than to middle clouds (Hatzianastassiou et al., 2004a). Among the other parameters, only the cloud scattering optical depth of lowand mid-level clouds introduces significant increases in the OSR at TOA, equal to 0.9 and $0.62 \mathrm{Wm}^{-2}$, respectively. The contribution of the rest of the parameters to the overall OSR trend is minor. Therefore, the observed trend in the tropical mean OSR at TOA (as computed by our model) over the period 1984-2000, is mostly explained by changes in cloud 
amount, and especially those of low-level clouds, rather than any change in other cloud properties or other physical input parameter. More specifically, the OSR radiative forcing due to low-level clouds represents about $78 \%$ of the total OSR forcing induced by all parameters. Nevertheless, it should be pointed out that there are still issues as to the reliability of ISCCP cloud trends. For example, although the most serious calibration changes, which represented an important problem (Klein and Hartman, 1993; Rossow and Cairns, 1995), have been adjusted for in the last ISCCP-D series data, there are still uncertainties related with the dependence of trends in ISCCP cloudiness on view angle (e.g. Campbell, 2004).

\section{Conclusions}

To summarise, a model analysis was performed, using a SW radiative transfer model along with mean monthly climatological data for key physical parameters taken from the ISCCP-D2 data set and the NCEP/NCAR and ECMWF global reanalysis projects. Our results indicate that there has been a decrease in the mean tropical and subtropical $\left(30^{\circ} \mathrm{S}-30^{\circ} \mathrm{N}\right)$ OSR at TOA, between January 1984 and December 2000 , of $1.9 \pm 0.3 \mathrm{Wm}^{-2} /$ decade. This decrease is in good agreement with the results of Wielicki et al. (2002a,b), and close to the computed value of $2.5 \pm 0.4 \mathrm{Wm}^{-2}$ derived from the long-term ERBE S-10N (WFOV NF edition 2) nonscanner OSR time series. The 17-year (1984-2000) time series of anomalies in both OSR flux at TOA and various physical parameters were constructed as departures from the corresponding 17-year mean values. The performed correlation analysis between mean monthly pixel-level anomalies of model OSR flux at TOA and VIS/IR ISCCP-D2 total cloud cover over the tropical and subtropical regions $\left(30^{\circ} \mathrm{S}-\right.$ $30^{\circ} \mathrm{N}$ ), has shown a significant correlation, with a coefficient equal to 0.79 . Our analysis of the inter-annual and longterm variability of the various parameters determining the OSR at TOA, has shown that the most important contribution to the observed OSR trend comes from a decrease in VIS/IR low-level cloud amount over the period 1984-2000, followed by smaller decreasing trends in mid- and high-level cloudiness. Opposite but small trends are introduced by an increase in cloud scattering optical depth of low clouds, and a smaller increase for middle-level clouds. It should be pointed out, however, that there are still uncertainties related to the trends in ISCCP-D2 clouds, and especially the low-level ones. Overall, our model is able to reproduce the observed decadal-scale decreasing trend and the patterns of the long-term variability of OSR at TOA over tropical regions. This trend is due to corresponding decreasing trend in ISCCP-D2 cloudiness, especially the low-level one. Although this can be expected, given the sensitivity of radiative transfer calculations to the input variables, in particular clouds, and despite possible uncertainties and problems with ISCCP cloud data, it is very interesting that we obtain good agreement between the model computed trend in OSR and that derived from ESRB data. Finally we note that the OSR trend of $1.9 \pm 0.3 \mathrm{Wm}^{-2} /$ decade as computed by our model, is balanced by the OLR trend of $1.9 \pm 0.2 \mathrm{Wm}^{-2} /$ decade computed by Hatzidimitriou et al. (2004) using a corresponding deterministic LW radiative transfer model, resulting thus in an absence of any decadal trend in the net (all-wave) radiation budget at TOA during the study period.

Acknowledgements. This research was funded by the European Commission (contract: EVK2-CT-2000-00055) under the Thematic Program: Preserving the Ecosystem; Key Action 2: Global Change, Climate and Biodiversity. The ISCCP-D2 data were obtained from the NASA Langley Research Center (LaRC) Atmospheric Sciences Data Center (ASDC). The NCEP/NCAR Global Reanalysis Project data were taken from the National Oceanic and Atmospheric Administration (NOAA) Cooperative Institute for Research in Environmental Sciences (CIRES) Climate Diagnostics Center, Boulder, Colorado, USA. The ECMWF data were obtained from the Data Ordering Service of ECMWF. The GADS aerosol data were obtained from the Meteorological Institute of the University of Munich, Germany (http://www.meteo. physik.uni-muenchen.de/strahlung/aerosol/aerosol.htm).

Edited by: A. Nenes

\section{References}

Allan, R. P., Ringer, M. A., Pamment, J. A., and Slingo, A.: Simulation of the Earth's radiation budget by the European Centre for Medium-Range Weather Forecasts 40-year reanalysis (ERA40), J. Geophys. Res., 109, D18107, doi:10.1029/2004JD004816, 2004.

Allan, R. P. and Slingo, A.: Can current climate forcings explain the spatial and temporal signatures of decadal OLR variations?, Geophys. Res. Lett., 29(7), 1141, doi:10.1029/2001GL014620, 2002.

Barkstrom, B., Harrison, E., Smith, G., Green, R., Kibler, J., Cess, R., and ERBE Science team: Earth Radiation Budget Experiment (ERBE) archival and April 1985 results, Bull. Am. Meteorol. Soc., 70, 1254-1262, 1989.

Campbell, G. G.: View angle dependence of cloudiness and the trend in ISCCP cloudiness, 13th AMS conference on Satellite Meteorology and Oceanography, 20-24 September 2004, Norfolk, VA, Abstr. No. P6.7, 2004.

Chen, J., Carlson, B. E., and Del Genio, A. D.: Evidence for strengthening of the tropical general circulation in the 1990s, Science, 295, 838-841, 2002.

Ellis, T. D., Stephens, G. L., and Thompson, D. W.: Evaluation of cloud amount trend and connections large scale dynamics, 15th Symposium on Global Change and Climate Variations, The 84th AMS Annual Meeting, 11-15 January 2004, Seattle, WA, USA, Abstr. No. 5.7, http://reef.atmos.colostate.edu/ellis/ AMStalk.html, 2004.

Hatzianastassiou, N. and Vardavas, I.: Shortwave radiation budget of the Northern Hemisphere using International Satellite Cloud Climatology Project and NCEP/NCAR climatological data, J. Geophys. Res., 104, 24 401-24 421, 1999. 
Hatzianastassiou, N. and Vardavas, I.: Shortwave radiation budget of the Southern Hemisphere using ISCCP C2 and NCEP/NCAR climatological data, J. Climate, 14, 4319-4329, 2001.

Hatzianastassiou, N., Fotiadi, A., Matsoukas, C., Drakakis, E., Pavlakis, K. G., Hatzidimitriou, D., and I. Vardavas: Long-term Global Distribution of Shortwave Radiation Budget at the Top of Atmosphere, Atmos. Chem. Phys., 4, 1217-1235, 2004a,

SRef-ID: 1680-7324/acp/2004-4-1217.

Hatzianastassiou, N., Katsoulis, B., and Vardavas, I.: Global distribution of aerosol direct radiative forcing in the ultraviolet and visible arising under clear skies, Tellus, 56B, 51-71, 2004b.

Hatzidimitriou, D., Vardavas, I., Pavlakis, K. G., Hatzianastassiou, N., Matsoukas, C., and Drakakis, E.: On the decadal increase in the tropical mean outgoing longwave radiation for the period 1984-2000, Atmos. Chem. Phys., 4, 1419-1425, 2004,

\section{SRef-ID: 1680-7324/acp/2004-4-1419.}

Hodges, K. I., Chappell, D. W., Robinson, G. J., and Yang, G.: An improved algorithm for generating global window brightness temperatures from multiple satellite infrared imagery, J. Atmos, Ocean Tech., 17, 1296-1312, 2000.

Intergovernmental Panel on Climate Change (IPCC): Climate Chance 2001: The Scientific Basis, edited by: Houghton, J., Ding, Y., Griggs, D. J., Noguer, M., Van der Linden, P. J., Dai, X., Maskell, K., and Johnson, C. A., 881 pp., Cambridge University Press, Cambridge, 2001.

Jacobowitz, H., Stowe, L. L., Ohring, G., Heidinger, A., Knapp, K., and Nalli, N. R.: The Advanced Very High Resolution Radiometer Pathfinder Atmosphere (PATMOS) Climate Dataset: A resource for Climate Research, Bull. Am. Meteor. Soc., 84, 785793, 2003.

Klein, S. A. and Hartmann, D. L.: Spurious changes in the ISCCP data set, Geophys. Res. Lett., 20, 455-458, 1993.

Koepke, P., Hess, M., Schult, I., and Shettle, E. P.: Global aerosol data set, Rep. No. 243, Max-Plank Institute fur Meteorologie, 44 pp., Hamburg Germany, 1997.
Lin, B., Wong, T., Wielicki, B. A., and Hu, Y.: Examination of the Decadal Tropical Mean ERBS Nonscanner Radiation Data for the Iris Hypothesis, J. Climate, 17, 1239-1246, 2004.

Luo, Z., Rossow, W. B., Inoue, T., and Stubenrauch, C. J.: Did the eruption of the Mt. Pinatubo volcano affect cirrus properties?, J. Climate, 15, 2806-2820, 2002.

Rossow, W. B. and Cairns, B.: Monitoring changes of clouds, Climate Change, 31, 305-347, 1995.

Rossow, W. B. and Schiffer, R. A.: Advances in understanding clouds from ISCCP, Bull. Am. Meteorol. Soc., 80, 2261-2287, 1999.

Rossow, W. B., Walker, A. W., Beuschel, D. E., and Roiter, M. D.: International Satellite Cloud Climatology Project (ISCCP). Documentation of new cloud datasets, 115 pp., World Meteorol. Org., Geneva, 1996.

Vardavas, I. M. and Koutoulaki, K.: A model for the solar radiation budget of the Norther Hemisphere: Comparison with Earth Radiation Budget Experiment data, J. Geophys. Res., 100, 73037314, 1995.

Wang, P.-H., Minnis, P., Wielicki, B. A., Wong, T., and Van, L. B.: Satellite observations of long-term changes in tropical cloud and outgoing longwave radiation from 1985 to 1998 , Geophys. Res. Lett., 29, 10, 1397, doi:10.1029/2001GL014264, 2002.

Wielicki, B. A., Wong, T. M., Allan, R. P., Slingo, A., Kiehl, J. T., Soden, B. J., Gordon, C. T., Miller, A. J., Yang, S.-K., Randall, D. A., Robertson, F., Susskind, J., and Jacobowitz, H.: Evidence for large decadal variability in the tropical mean radiative energy budget, Science, 295, 841-844, 2002a.

Wielicki, B. A., Del Genio, A. D., Wong, T., Chen, J., Carlson, B. A., Allan, R. P., Robertson, F., Jacobowitz, H., Slingo, A., Randall, D. A., Kiehl, J. T., Soden, B. J., Gordon, C. T., Miller, A. J., Yang, S., and Susskind, J.: Changes in Tropical Clouds and Radiation, Response, Science, 296, p. 2095, 2002 b.

Zhang, Y., Rossow, W. B., Lacis, A. A., Oinas, V., and Mishchenko, M. I.: Calculation of radiative fluxes from the surface to top of atmosphere based on ISCCP and other global data sets: Refinements of the radiative transfer model and the input data, J. Geophys. Res., 109, D19105, doi:10.1029/2003JD004457, 2004. 